Article

\title{
Electric Roads: Analyzing the Societal Cost of Electrifying All Danish Road Transport
}

\author{
Gabriel Domingues-Olavarría ${ }^{1, *, t, \ddagger}$ (D) , Francisco J. Márquez-Fernández ${ }^{1, \ddagger}$, Pontus Fyhr ${ }^{2, \ddagger}$, \\ Avo Reinap ${ }^{1}$ and Mats Alaküla ${ }^{1}$ \\ 1 Division Industrial Electrical Engineering and Automation, Department of Biomedical Engineering, \\ Lund University, SE-221 00 Lund, Sweden; fran.marquez@iea.lth.se (F.J.M.-F.); avo.reinap@iea.lth.se (A.R.); \\ mats.alakula@volvo.com (M.A.) \\ 2 Division Production and Materials Engineering, Department of Mechanical Engineering, Lund University, \\ SE-221 00 Lund, Sweden; pontus.fyhr@iprod.lth.se \\ * Correspondence: gabriel.domingues@iea.lth.se; Tel.: +46-046-222-4582 \\ + Current address: IEA, LTH, Box 118, SE-221 00 Lund, Sweden. \\ $\ddagger$ These authors contributed equally to this work.
}

Received: 14 May 2018; Accepted: 3 June 2018; Published: 7 June 2018

check for updates

\begin{abstract}
Electric Road Systems (ERS) have emerged as an alternative to deal with the main drawbacks that battery electric vehicles present (i.e., higher cost, short driving range, long charging times, etc.). This paper analyses the societal cost of electrifying all road transport in Denmark under four different scenarios. The first scenario considered in this study is based on today's approach of having electric vehicles with high battery capacity and fast charging stations, the remaining scenarios study the cost of implementing different ERS at a national level. The results clearly show the benefits of implementing road bound electric road solutions that can be used both by commercial and passenger vehicles.
\end{abstract}

Keywords: battery electric vehicle (BEV); fleet; charging; dynamic charging; cost

\section{Introduction}

Denmark has the goal of becoming independent from fossil fuels by 2050, as it is outlined in their "Energy Strategy 2050" [1]. In order to achieve this goal, the transport sector must transition from fossil fuels (95\% of all the energy consumed by this sector [2]) towards renewable energy sources. Moreover, such a transition would have a significant impact on the total consumption of fossil fuels in the country as transport accounts for $66 \%$ of the total energy consumption from non-renewable sources in Denmark.

Within the Danish transport sector, road transport presents a particularly interesting case, as it is responsible for $75 \%$ of the energy consumed in this sector. Therefore, in order for Denmark to achieve their goal of being fossil fuel independent, it must find a cost-effective way of using renewable energy sources for road transport without modifying, in a significant way, the driving patterns of private and commercial vehicles.

Battery electric vehicles (BEV) are one of the most promising and popular technologies to lead this energy transition. However, this technology still presents some drawbacks that need to be overcome such as its higher cost, limited driving range and longer charging times when compared with conventional vehicles. In this context, Electric Road Systems (ERS) that allow BEV to charge while driving [3] have emerged as an alternative to deal with the main drawbacks of BEV. Since ERS are expected to be deployed in highways and roads connecting urban and industrial areas, the required battery capacity in the vehicles can be reduced without sacrificing the range and simultaneously 
reducing the vehicle's cost. Moreover, the fact that charging is performed while driving eliminates the need to stop at fast charging stations. Despite all the aforementioned advantages, since the implementation of a nationwide ERS requires a significant investment, it is necessary to evaluate the different ERS technologies in order to determine which one is the most cost-effective for the Danish society. Such a study must consider the composition of the Danish automotive fleet, its usage patterns and the existing road network.

A study quantifying the societal cost of electrifying all road transport both by means of battery packs and high power static charging, and by different ERS technologies have been previously carried out for the particular case of Sweden [4]. It is shown in that work that the cost savings due to having a vehicle fleet with a smaller battery packs largely exceed the cost of building an ERS infrastructure when most vehicle types can take advantage of such infrastructure. This conclusion is further confirmed in [5] where a lower "electromobility equivalent energy cost" is achieved when the infrastructure is shared between commercial and private vehicles.

Following these works, this paper aims to investigate the societal cost of electrifying all Danish road transport with and without ERS. To do so, four different scenarios are evaluated. In the first one, electrification is achieved only by means of big battery packs and high power static charging stations. The remaining three imply a nationwide implementation of different ERS technologies, namely overhead lines, road bound inductive and road bound conductive. The contribution of this paper to the existing academic literature is twofold: first, it shows that the methodology previously developed to analyze the implications of electrifying the Swedish automotive fleet under different scenarios can be directly applied to the study of other nationwide fleets; second, by comparing the results obtained when performing the same study in both countries, it is possible to better understand the impact of the fleet composition, road infrastructure and energy costs on the societal cost of the proposed scenarios.

\section{Electric Road Systems}

In this section, a review of the most promising ERS is presented. Without focusing on particular solutions, ERS technologies can be classified depending on their physical location with respect to the road and the type of energy transfer. Following this criteria, five different groups can be distinguished in the literature [6-14]: overhead conductive, road bound conductive, road bound inductive, road bound capacitive and road side conductive.

\subsection{Overhead Conductive}

Overhead conductive electric roads consist of two supply lines placed above the road at a height of around five meters. The vehicles need to be equipped with a connection device similar to a pantograph in order to establish contact with the supply lines. Additionally, this connection device must compensate both the lateral and vertical movements of the vehicle respect to the supply lines. This technology is only suitable to supply vehicles that are relatively high (trucks and buses) as mounting the connection device in smaller vehicles would be impractical. Moreover, due to the fact that the supply lines are hard to be accidentally reached by humans or animals, long stretches can be electrified at the same time $(>1 \mathrm{~km})$.

This technology is currently being tested in public roads in Sanviken, Sweden [6], where contact lines supplying a 650-750 V DC are placed in a two-kilometer stretch of highway and plug-in hybrid trucks equipped with pantographs connect to them in order to drive in full electric mode.

Despite being a relatively mature technology in other applications such as trolley buses and trams, higher driving speeds and possible higher utilization of the infrastructure introduce new challenges that need to be addressed. 


\subsection{Road Bound Conductive}

The term road bound ERS refers to a group of dynamic charging solutions that are characterized by presenting power conductors placed in close proximity to the surface of the road. An electrical connection between the ERS and the vehicle is established by means of a retractable pick-up, placed underneath the vehicle, that makes contact with the power conductors. This family of solutions tend to present significantly shorter energized segments in comparison with overhead ERS, as the conductors are placed in easy reach of humans and animals. The design of both the pick-up and the power conductors on the road depend heavily on the specific road bound conductive ERS solution.

For example, in [7], the power conductors are placed inside grooves made to the surface of the road, similar to a slot car. In this system, segments of around $50 \mathrm{~m}$ are energized when the vehicle is on top of them. One advantage of this solution is that it allows the energy supply to be either AC (reducing the cost of infrastructure) or DC (reducing the cost on board the vehicles).

On the other hand, an ERS solution is presented in [8] where two flat conductors are placed in the middle of the lane, parallel to the road. Segments of $22 \mathrm{~m}$ are energized in order to supply the vehicle with $750 \mathrm{~V}$ DC. This solution comes inspired from previous experiences in trams and railways.

Another approach is shown in [9], where the conductors are placed a few centimeters above the surface of the road in a single track. Unlike previous concepts, the positive and negative terminals are not placed next to each other. Instead, this solution proposes placing the terminals in-line with each other, alternating positive and negative segments with some insulation distance in between segments. In order to close the electrical circuit, any vehicle needs to be in contact with at least two segments (one positive and one negative). For this reason, the segment length needs to be significantly smaller than previous concepts $(1 \mathrm{~m})$, which can be perceived as an advantage in terms of safety as only the segments directly underneath the vehicle are electrified in a given point in time.

\subsection{Road Bound Inductive}

In an inductive, ERS energy is transferred from the road to the vehicle without the need for a conductive connection. This is achieved by means of two sets of coils, the primary (placed on the road) and the secondary (placed underneath the vehicle). Energy is transferred from the primary to the secondary coil by magnetic induction, similar to a transformer.

Despite the maturity of inductive energy transfer in consumer electronics and static charging of $\mathrm{EV}$, new challenges come when this technology is used for dynamic charging. Among these challenges are the need for a good lateral and vertical tolerance to misalignments, as keeping the coils at the same relative position while the vehicle is moving is not practical, and the need for a high power density on the secondary coil, in order to minimize the added weight to the vehicle.

An example of an inductive ERS was demonstrated in 2009 by KAIST [10], as part of the OLEV project. Moreover, an economical analysis of this technology is presented in [11] showing that the cost reductions due to the downsizing of the required battery pack for the same driving mission are greater than the cost of installing the dynamic charging infrastructure.

\subsection{Road Bound Capacitive}

Another approach to contact less energy transfer to a vehicle while in motion is through capacitive power transfer. In this case, a capacitive coupling is built between metal plates on the road and the vehicle. This coupling is used to transfer high frequency power from the road to the vehicle.

The main advantage of this system is the simplicity and low cost of the electrodes as no coupling coils are needed. On the other hand, high frequency inverters and rectifiers are needed for this implementation, which can lead to a higher system cost.

This technology has been shown in [12] where a capacitive ERS able to deliver $900 \mathrm{~W}$ to the battery is implemented and tested on a single seater vehicle in a $2.4 \mathrm{~m}$ stretch. This technology requires 
additional work to increase both the efficiency and power transfer capabilities in order to be applicable to more conventional vehicles.

\subsection{Road Side Conductive}

Conductive ERS are not limited to be placed above or below the vehicle, and the Japanese original equipment manufacturer (OEM) Honda has proposed to place the power conductors on the side of the road [13], which allows both passenger and heavy vehicles to take advantage of the infrastructure while keeping the road surface unchanged. This can potentially translate into lower maintenance cost for the road and the installation cost for the ERS.

This system has been tested at transfer powers of up to $180 \mathrm{~kW}$ and driving speeds between 5 and $156 \mathrm{~km} / \mathrm{h}$ [14]. However, further testing on public roads is necessary in order to ensure the reliability and safety of the system.

A representation of all the aforementioned ERS technologies is depicted in Figure 1, where the power supply is represented in blue and the power pick-up is shown in red. In the upcoming sections of this paper, only the first three ERS technologies are considered as currently they are the most mature [15] and the ones where most of the research has been carried out.

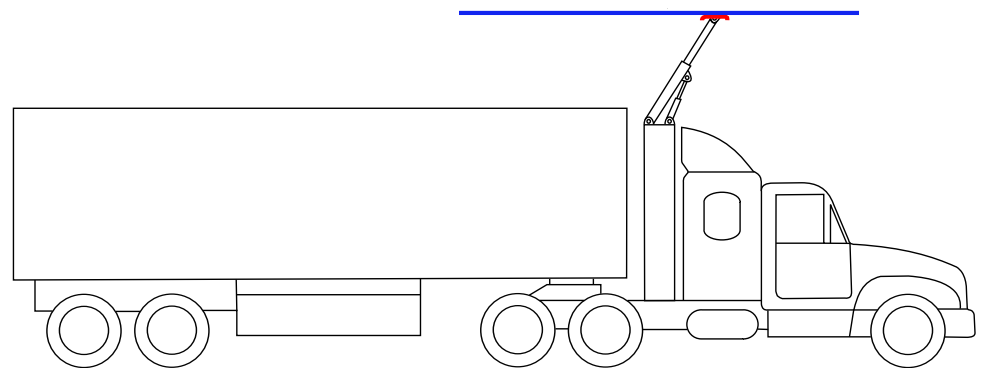

(a)

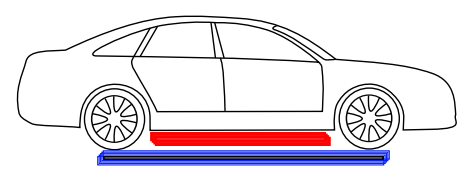

(c)

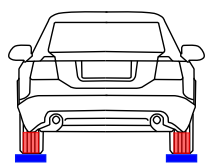

(d)

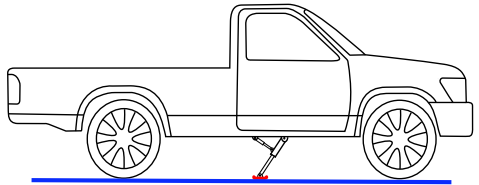

(b)

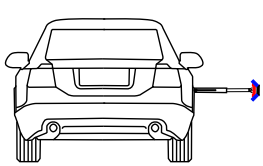

(e)

Figure 1. Different electric road technologies. Power supply in blue and power take off in red. (a) overhead conductive; (b) road bound conductive; (c) road bound inductive; (d) road bound capacitive; (e) road side conductive.

\section{The Danish Case}

In a similar fashion as it is presented in [4], the Danish automotive fleet of $3.3 \mathrm{M}$ vehicles is divided in four segments according to driving patterns and vehicle weight. The first and most numerous segment (2.8 M vehicles) includes all light duty vehicles (LDV) with a gross combination weight rating (GCWR) below 3.5 tons and is dominated by privately owned passenger cars $(2.4 \mathrm{M})$ and vans (400 k). Vehicles in this segment tend to have a relatively low utilisation compared to other segments and, on average, drive shorter distances. The second segment includes all buses driving intra-city routs $(7 \mathrm{k})$; they are characterized for having a high utilization but a low average driving speed. No limits are imposed on the gross combined weight rating (GCWR) of the vehicles in the second group, therefore single-decker, double-decker and multi-articulated buses are all part of this segment. Distribution trucks (16 k) with GCWR between 3.6 and 16 tons compose the third segment-these vehicles are extensively used, driving both inter and intra-city routs. The final segment is composed of 
heavy vehicles used for long hauling ( $32 \mathrm{k}$ ) - this includes long haul trucks and couch buses. Outside of this classification, two-wheelers (200 k) and agricultural, recreational and specialized vehicles (227 k) remain, as they only represent a small fraction of the $\mathrm{CO}_{2}$ emitted by road transport and their electrification requires more specifically tailored solutions.

The societal cost of electrifying the whole Danish automotive fleet not only depends on the fleet composition, but also on the extension of the road network and driving patterns of the population, as these factors affect the required investments in infrastructure for some electrification scenarios, as well as the potential cost savings in fuel. Although Denmark is a relatively small country $\left(43,000 \mathrm{~km}^{2}\right)$, it counts with a dense road network with a total length of $73,500 \mathrm{~km}$, out of which $4509 \mathrm{~km}$ are highways and dual carriageways [16]. These are depicted in Figure 2. In total, 43.4 TWh are consumed every year by road transport in Denmark, which accounts for $34 \%$ of the total energy consumed in the country [2].

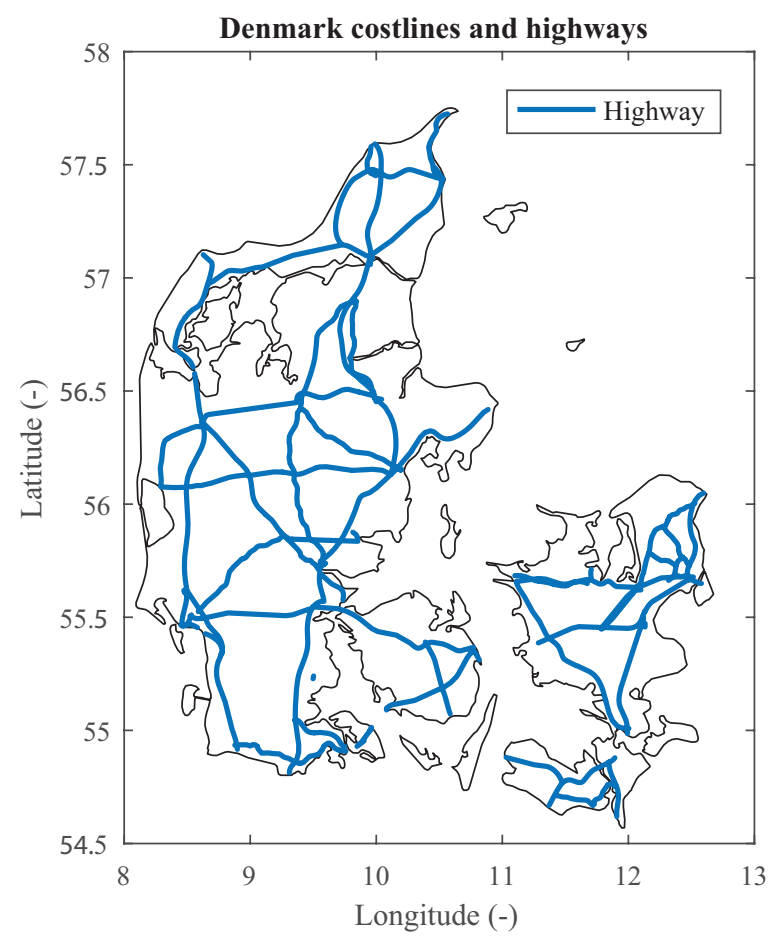

Figure 2. Extent of the Danish highway network.

\section{Cost Modeling and Assumptions}

In order to assess the societal cost of electrifying all road transport in Denmark under different scenarios, it is necessary to account for the required investments in charging infrastructure (both static and dynamic), the additional electromobility related on-board components, as well as the savings due to the removal of the conventional powertrain and the lower energy cost and consumption that electric vehicles offer in comparison with their conventional counterpart.

The cost of the ERS infrastructure is modeled as presented in [5], which is based on the conductive solutions on preliminary data obtained from the existing pilot test sites in Sweden, and for the inductive solution approximated based on the component and installation costs estimated for a potential system layout. Similarly, the cost of the required connection devices whether it is a receiver coil or an automotive conductive pick-up are estimated based on figures reported by [7-9]. It is worth keeping in mind that, as ERS are relatively new technologies, accurate cost estimations are difficult to obtain; however, in upcoming sections of this paper, it is shown that the impact of significant variations in the estimated cost of the ERS does not change the results in a considerable manner. Furthermore, 
the maintenance cost may vary significantly between each individual technical solution, but data on maintenance costs is lacking and have been kept proportional to the cost of deployment.

Besides the ERS, Li-ion batteries also add uncertainty to the total system cost estimations presented. In recent years, the cost of Li-ion batteries at pack level has been steadily decreasing, and, by 2030, a figure between 150 and $300 € / \mathrm{kWh}$ can be expected [17]. However, following the projection in [18], a figure of $100 € / \mathrm{kWh}$ is used in this work, as it poses a more difficult challenge for the deployment of ERS.

On the other hand, the cost of all of the different power electronic converters required on board the vehicle (traction inverter, DC/DC converters to supply auxiliary loads or to transfer energy between external sources and the on-board storage, etc) is estimated based on the work presented in [19], where the different components inside the converter are accurately sized based on the demands of the application and the cost of manufacturing/purchasing the different components, assembling and testing the converter are accounted for.

In a similar fashion, for each vehicle segment, the electrical machine(s) are optimized and their cost is calculated as presented in [20], including not only the material, but also the direct manufacturing cost. It is important to notice, that as the aim of this work is to estimate the societal cost of electrifying all the road fleet under different scenarios, profits and overhead costs are not taken into consideration. Additionally, the savings due to the removal of the conventional powertrain and fuel tank are included in the estimation [21].

Finally, the fuel and electricity cost are assumed to be $1.34 € /$ litre and $0.135 € / \mathrm{kWh}$ based on current figures in Denmark. Moreover, $20 \%$ VAT is subtracted from both as only societal cost is being considered in this study.

\section{Scenarios}

The societal cost of electrifying the whole Danish automotive fleet is studied under four different scenarios:

(1) Large batteries: In this scenario, the electrification of all road transport is achieved by the sole use of batteries and high power static charging. LDVs are assumed to have enough battery capacity to cover $240 \mathrm{~km}$ and a network of fast chargers is spread through the country allowing them to charge at $120 \mathrm{~kW}$; additionally, a $6 \mathrm{~kW}$ on-board charger is included in each vehicle in order to charge over night. City buses and distribution trucks have enough battery range to cover a full day of operation (500 kWh and $340 \mathrm{kWh}$, respectively) and charging is performed over night at $70 \mathrm{~kW}$ and $30 \mathrm{~kW}$, respectively. Finally, long haul trucks are equipped with enough battery capacity ( $480 \mathrm{kWh}$ ) to drive for about two hours $(200 \mathrm{~km})$ before needing to stop at a charging station to replace the tractor for a fully charged one, since it is not realistic to assume a thirty-minute break every two hours for charging. This tractor swapping requires increasing the number of tractors in the fleet in order to keep the same flow of goods.

(2) Overhead electric road: This scenario introduces overhead ERS on all major roads in the country $(4500 \mathrm{~km})$ for the exclusive benefit of long haul trucks and coach buses. This reduces the required battery capacity for the aforementioned vehicles down to $120 \mathrm{kWh}$ (equivalent to $50 \mathrm{~km}$ of range). This technology, however, does not affect the remaining vehicles of the fleet, so they remain unchanged with respect to scenario 1 .

(3) Road bound inductive: The overhead ERS from scenario 2 is replaced by an inductive road bound solution. This means that LDVs can also take advantage of the dynamic charging infrastructure. As LDVs can now charge while they drive on all major roads, their required battery capacity can be reduced to provide about $50 \mathrm{~km}$ of driving range $(15 \mathrm{kWh})$. Moreover, opportunity charging is made available to city buses and distribution trucks, which also allows for reducing their battery capacity to $90 \mathrm{kWh}$ and $120 \mathrm{kWh}$, respectively.

(4) Road bound conductive: the inductive ERS from scenario 3 is replaced by a conductive solution, which is expected to be cheaper in terms of infrastructure but require additional components 
on board the vehicle in order to provide galvanic insulation between the electric supply from the road and the high voltage system on board the vehicle.

\section{Results and Discussion}

Using the cost models and assumptions previously presented, the societal cost of electrifying all road transport in Denmark is studied under the scenarios described in Section 5. The outcome of this study is shown in Figure 3 where the societal cost for each scenario is presented as a bar, which in turn is divided into the major cost contributions. The positive sections of the bars in the chart represent the investments required to achieve a full electrification of the fleet under the predefined conditions. On the other hand, the negative sections of the bars represent the societal savings associated with the absence of the conventional powertrain and the savings in energy cost due to the higher efficiency of the electric powertrain and lower cost of electricity compared to fossil fuels.

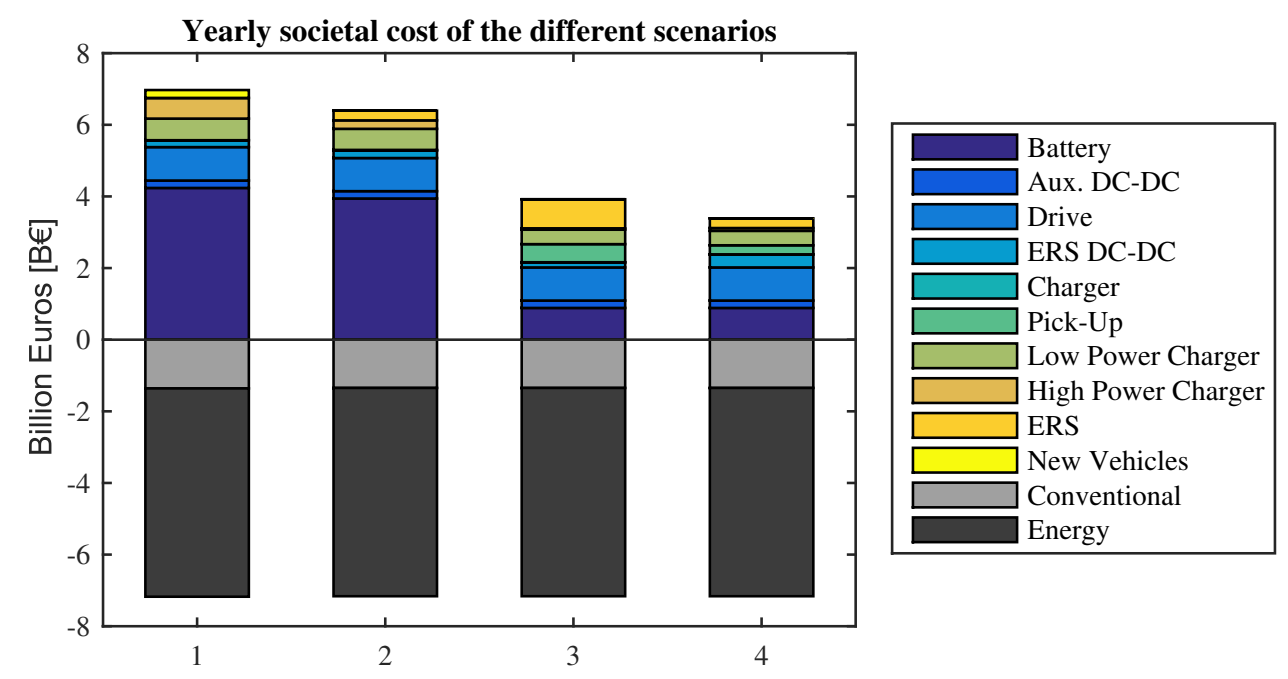

Figure 3. Societal cost of electrifying all road transport in Denmark under four different scenarios.

In Figure 3, it is possible to observe that, even for an optimistically low battery cost, the first scenario, using large batteries and high power static charging barely breaks even. This also indicates that, at current battery prices, long-range BEVs are not yet cost-effective from a societal perspective (unless additional factors such as lower maintenance cost are considered as well). Moreover, it can be noticed that, when only the long haul trucks benefit from the ERS (scenario 2), the societal cost is not significantly reduced with respect to the first scenario, since the major cost driver (the battery packs for LDVs) remains unchanged.

On the other hand, when road bound ERS are introduced (scenarios 3 and 4), a significant reduction in the societal cost can be observed. This is primarily due the fact that a large reduction in the battery capacity of LDVs (from $72 \mathrm{kWh}$ to $15 \mathrm{kWh}$ ) can be achieved without sacrificing the overall driving range or usability of these vehicles. In addition, it can be appreciated that, in these scenarios, the total battery cost is comparable to the cost of the other powertrain components, which makes these scenarios cost-effective even at higher battery costs. This is further confirmed in Figure 4a, where a sensitivity analysis is carried out on the battery cost. From this figure, it is clear that road bound solutions (either inductive or conductive) remain cost-effective even for battery costs above $300 € / \mathrm{kWh}$, which would make them cost-effective at today's battery prices.

Another assumption that is worth examining further is the required number or cost of fast charging stations for the LDV segment. In this study, the required number of fast chargers per vehicle is assumed to be the same as in [4]. As discussed in that work, this assumption can be argued and a more detailed optimization is needed in order to find the minimum number and size of fast charging 
stations that can cope with the peak demand for charging. However, as it can be seen in the sensitivity analysis presented in Figure $4 \mathrm{~b}$, the scenario that presents the highest sensitivity to this parameter is the first. This is mainly due to the high number of additional (very high power) charging stations needed to supply the long haul trucks. When the trucks are moved away from fast charging stations (scenario 2), societal cost becomes more insensitive to the cost of the static charging infrastructure.

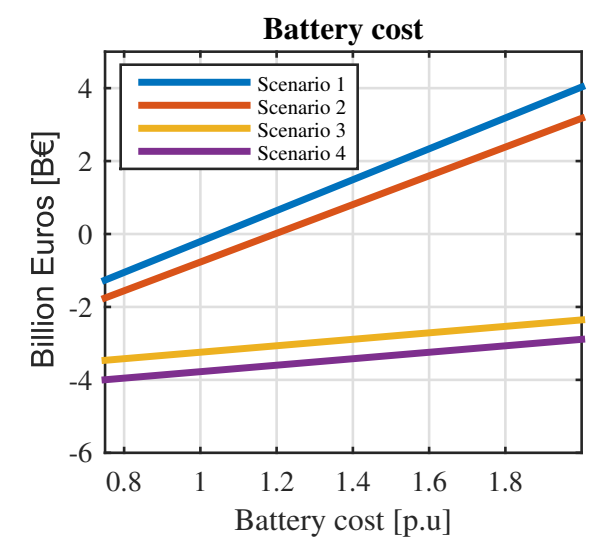

(a)

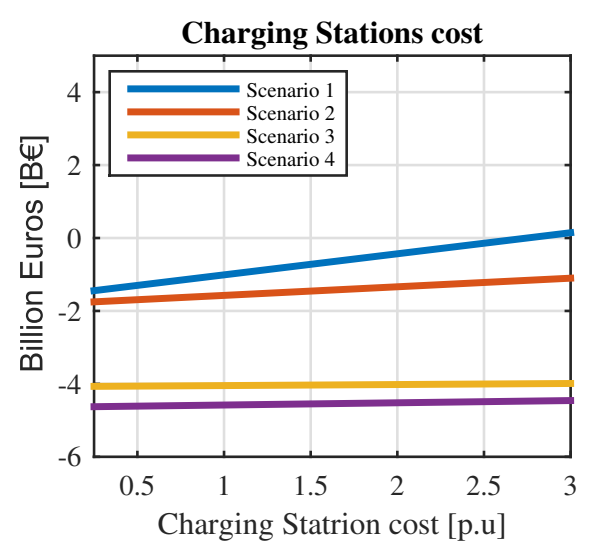

(b)

Figure 4. Sensitivity analysis on the battery and charging stations cost. (a) battery cost; (b) charging stations cost.

A clear conclusion from Figure 3 is that investments in ERS lower societal cost and that the advantages are even greater if LDVs can also benefit from the infrastructure. However, this study relies on cost figures for the ERS that are surrounded by uncertainty as these are relatively new technologies that are not currently being mass produced. Nonetheless, it is shown in Figure 5a that overhead ERS would still provide benefits when compared with scenario 1 even if the ERS cost was three times higher. Additionally, in Figure 5b, it can be observed that road bound conductive ERS remains as the most cost-effective solution even if its cost is increased by a factor of three.

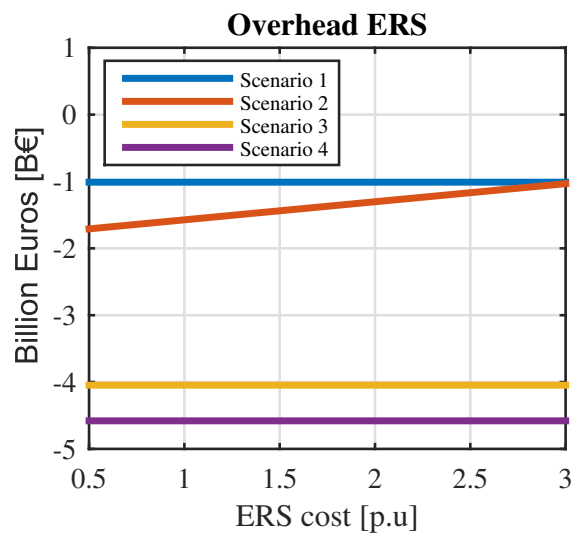

(a)

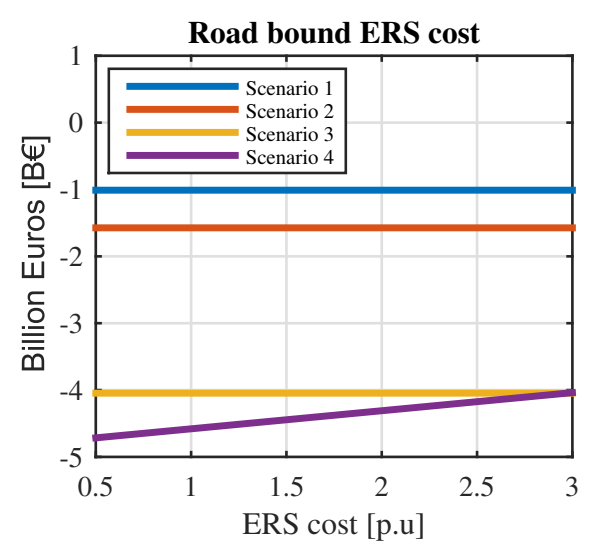

(b)

Figure 5. Sensitivity analysis on the ERS cost. (a) overhead conductive ERS cost; (b) road bound conductive ERS cost. 


\subsection{Comparison with the Swedish Case}

An interesting comparison can be made between the societal cost of electrifying the Danish and the Swedish automotive fleet as both countries have different fleet compositions, electricity and fuel prices, road network density and usage patterns. Figure 6 shows the percentage of savings relative to the required investment in electrification for both Sweden and Denmark in the scenarios described in this work. For absolute values on the Swedish case, refer to [4].

It can be observed that for the first two scenarios the differences between the relative savings in both countries are significant. The main reasons for this is that Sweden consumes a higher amount of energy per vehicle and has a remarkably low electricity cost. These factors increase the relative savings gap between the two countries. Interestingly, when a road bound inductive ERS is introduced, Denmark has a higher potential benefit than Sweden. This has to do with the fact that the number of vehicles per $\mathrm{km}$ of major road in Denmark is around 650, while, in Sweden, it is half of that, meaning that the infrastructure investment is spread among a higher number of vehicles in the Danish case. However, when the cost of the ERS infrastructure is reduced (moving from scenario 3 to 4 ), the difference in energy consumption and energy cost becomes the most significant factor again and the potential benefit becomes larger for Sweden.

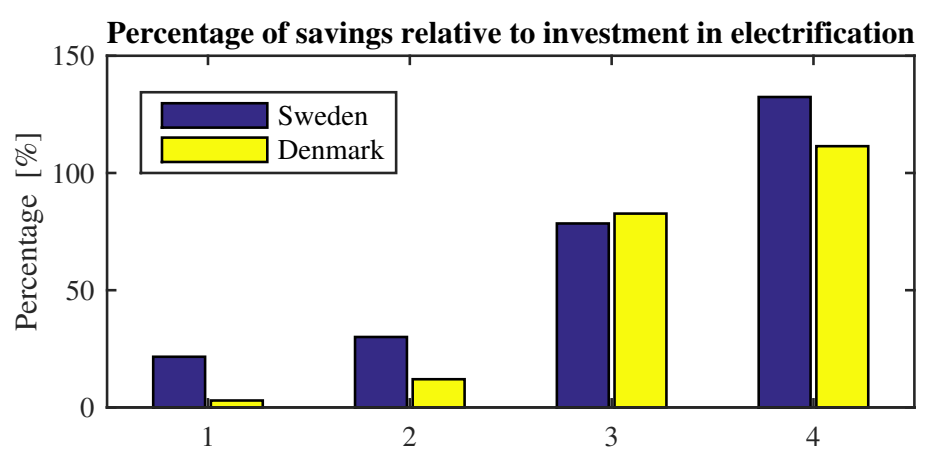

Figure 6. Savings comparison between Sweden and Denmark.

\section{Conclusions}

From the results shown in Figure 3 and the sensitivity studies in Figures 4 and 5, it is clear that ERS offers a potential to dramatically reduce the cost of vehicle electrification for a nation if the technology can be deployed at scale within the investment range and installed useful life used in this study. The technology selected needs to be accessible to both heavy and light vehicles, a difficult proposition as the operators of each vehicle category have different incentives. The marginal savings from scenario 1 to scenario 2, compared to the dramatically lower societal cost in scenarios 3 and 4 as shown in Figure 3, motivate why ERS should be available to all vehicle categories. The same result, when viewed as a percentage of savings relative to the cost of fossil based transport in Figure 6, shows an even clearer distinction.

In the comparison performed in Section 6.1, it is worth noticing how sensitive the savings are to the price of electricity. As Denmark is a country with higher population density and a more compact highway network than Sweden, the expected result of higher savings than the Swedish case only materialized in one out of four scenarios.

This study has shown that once the fleet is completely electrified, the use of an ERS that is accessible to all vehicle types significantly reduces the overall societal cost. In this context, an interesting topic for future research is the modelling and analysis of the transition period as well as finding the optimal way of rolling out the ERS infrastructure. Additionally, the inclusion of other alternatives to reduce the emissions derived from road transport, such as fuel cell and bio-fuel vehicles would broaden the understanding of the implications of different alternatives to current combustion engine vehicles. Moreover, in future work, different electrification scenarios should be analyzed considering 
international traffic flows and geography as cross-border standardization would be a prerequisite to the large scale deployment any ERS technology.

Author Contributions: Conceptualization, M.A.; Methodology, G.D.-O., F.J.M.-F., P.F.; Software, G.D.-O. and P.F.; Formal Analysis, G.D.-O., F.J.M.-F., P.F.; Investigation, G.D.-O., F.J.M.-F., P.F.; Data Curation, G.D.-O. and P.F.; Writing-Original Draft Preparation, G.D.-O., F.J.M.-F., P.F.; Writing-Review \& Editing, G.D.-O., F.J.M.-F. and P.F. and A.R.; Visualization, G.D.-O. and P.F.; Supervision, M.A. and A.R.; Project Administration, M.A.; Funding Acquisition, M.A.

Acknowledgments: The authors would like to thank the Swedish Energy Agency, projects EMCost and Multi-Functional Electric Axle and the Swedish Electromobility Centre.

Conflicts of Interest: The authors declare no conflict of interest.

\section{References}

1. Danish Government. Energy Strategy 2050: From Coal, Oil and Gas to Green Energy: Summary; The Danish Government: Copenhagen, Denmark, 2011.

2. Danish Energy Agency. Energy Statistics 2014; Danish Energy Agency: Copenhagen, Denmark, 2016.

3. Tongur, S.; Sundelin, H. The electric road system transition from a system to a system-of-systems. In Proceedings of the 2016 Asian Conference on Energy, Power and Transportation Electrification (ACEPT), Singapore, 25-27 October 2016; pp. 1-8, doi:10.1109/ACEPT.2016.7811529.

4. Fyhr, P.; Domingues-Olavarria, G.; Andersson, M.; Márquez-Fernández, F.J.; Bängtsson, H.; Alaküla, M. Electric Roads: Reducing the Societal Cost of Transport Electrification. In Proceedings of the 2017 IEEE Transportation Electrification Conference and Expo (ITEC), Chicago, IL, USA, 22-24 June 2017.

5. Márquez-Fernández, F.J.; Domingues-Olavarria, G.; Fyhr, P.; Lindgren, L.; Alaküla, M. Electric Roads: The importance of sharing the infrastructure among vehicle types. In Proceedings of the 2017 IEEE International Transportation Electrification Conference and Expo, Asia-Pacific (ITEC-AP), Harbin, China, 7-10 August 2017.

6. Danielsson, H.A.; Vagstedt, N.G. Worlds First Electric Road Opens in Sweden. Available online: https:// www.scania.com/group/en/worlds-first-electric-road-opens-in-sweden/ (accessed on 4 November 2016).

7. Asplund, G.; Rehman, B. Conductive feeding of electric vehicles from the road while driving. In Proceedings of the 2014 4th International Electric Drives Production Conference (EDPC), Nuremberg, Germany, 30 September-1 October 2014; pp. 1-9, doi:10.1109/EDPC.2014.6984418.

8. Alstom. APS—Ground Level Power Supply, 2017. Available online: http://www.alstom.com/productsservices/product-catalogue/rail-systems/Infrastructures/products/aps-ground-level-power-supply / (accessed on 4 May 2017).

9. Elonroad. Elonroad Electric Road Technology, 2017. Available online: http:/ / elonroad.com (accessed on 4 May 2017).

10. Suh, I.S.; Kim, J. Electric vehicle on-road dynamic charging system with wireless power transfer technology. In Proceedings of the 2013 IEEE International Electric Machines Drives Conference (IEMDC), Chicago, IL, USA, 12-15 May 2013; pp. 234-240, doi:10.1109/IEMDC.2013.6556258.

11. Jeong, S.; Jang, Y.J.; Kum, D. Economic Analysis of the Dynamic Charging Electric Vehicle. IEEE Trans. Power Electron. 2015, 30, 6368-6377, doi:10.1109/TPEL.2015.2424712.

12. Sakai, N.; Itokazu, D.; Suzuki, Y.; Sakihara, S.; Ohira, T. Single-seater vehicle prototype experiment powered by high frequency electric field on an asphalt-paved roadway. In Proceedings of the 2016 6th International Electric Drives Production Conference (EDPC), Nuremberg, Germany, 30 November-1 December 2016; pp. 101-104, doi:10.1109/EDPC.2016.7851321.

13. Zhang, W.; Wong, S.C.; Tse, C.K.; Chen, Q. An Optimized Track Length in Roadway Inductive Power Transfer Systems. IEEE J. Emerg. Sel. Top. Power Electron. 2014, 2, 598-608, doi:10.1109/JESTPE.2014.2301460.

14. Tajima, T.; Tanaka, H.; Fukuda, T.; Nakasato, Y.; Noguchi, W.; Katsumasa, Y.; Aruga, T. Study of High Power Dynamic Charging System; SAE Technical Paper; SAE International: Warrendale PA, USA, 2017, doi:10.4271/2017-01-1245.

15. Sundelin, H.; Gustavsson, M.G.H.; Tongur, S. The maturity of electric road systems. In Proceedings of the 2016 International Conference on Electrical Systems for Aircraft, Railway, Ship Propulsion and Road Vehicles 
International Transportation Electrification Conference (ESARS-ITEC), Toulouse, France, 2-4 November 2016; pp. 1-5, doi:10.1109/ESARS-ITEC.2016.7841380.

16. Danish Ministry of Transport. The Danish Transport System-Facts and Figures; Danish Ministry of Transport: Copenhagen, Denmark, 2011.

17. Nykvist, B.; Nilsson, M. Rapidly falling costs of battery packs for electric vehicles. Nat. Clim. Chang. 2015, 5, 329-332.

18. McKinsey and Company. Electrifying Insights: How Automakers Can Drive Electrified Vehicles and Profitability; McKinsey and Company: Brussels, Belgium, 2017.

19. Domingues-Olavarria, G.; Fyhr, P.; Reinap, A.; Andersson, M.; Alakula, M. From Chip to Converter: A Complete Cost Model for Power Electronics Converters. IEEE Trans. Power Electron. 2017, 32, 8681-8692, doi:10.1109/TPEL.2017.2651407.

20. Domingues-Olavarria, G.; Márquez-Fernández, F.; Fyhr, P.; Reinap, A.; Andersson, M.; Alakula, M. Scalable Performance, Efficiency and Thermal Models for Electric Drive Components Used in Powertrain Simulation and Optimization. In Proceedings of the 2017 IEEE Transportation Electrification Conference and Expo (ITEC), Chicago, IL, USA, 22-24 June 2017.

21. Gustafsson, T.; Johansson, A. Comparison between Battery Electric Vehicles and Internal Combustion Engine Vehicles fueled by Electrofuels; Chalmers Tekniska HöGskola: Göteborg, Sweden, 2015.

(C) 2018 by the authors. Licensee MDPI, Basel, Switzerland. This article is an open access article distributed under the terms and conditions of the Creative Commons Attribution (CC BY) license (http://creativecommons.org/licenses/by/4.0/). 